\title{
Investigation of Efflux-Mediated Tetracycline Resistance in Shigella Isolates Using the Inhibitor and Real Time Polymerase Chain Reaction Method
}

\author{
Shadi Shahsavan ${ }^{1}$, Parviz Owlia ${ }^{2}$, Abdolaziz Rastegar Lari ${ }^{3}$, Bita Bakhshi ${ }^{4}$, Maliheh Nobakht ${ }^{1,5 *}$ \\ 1. Antimicrobial Resistance research center, Iran University of Medical science, Tehran, Iran \\ 2. Molecular Microbiology Research Center, Shahed University, Tehran, IR Iran \\ 3. Dept. of Microbiology, Faculty of Medicine, Iran University of Medical science, Tehran, Iran \\ 4. Dept. of Microbiology, Faculty of Medicine, Tarbiat Modares University, Tehran, Iran \\ 5. Dept. of Anatomy, Faculty of Medicine, Iran University of Medical science, Tehran, Iran
}

\begin{tabular}{l} 
KEYWORDS \\
\hline Shigella \\
Tetracycline resistance \\
Efflux pump \\
Real-Time PCR \\
\\
Article Info
\end{tabular}

Received 02 Jan 2016

Accepted 27 Jan 2017

Published Online 05 Feb 2017;

\section{ABSTRACT}

Background: Shigella spp. are gram negative bacteria, which are of global public health importance. The growing of multidrug-resistant Shigella isolates are a major problem around the world.

Methods: Overall, 50 isolates of Shigella spp. from children diarrheic stools were studied. The isolates were identified and confirmed using biochemical, serological and molecular methods (ipaH, wbgZ and $r f c$ genes). Antimicrobial susceptibility test was done according to the Clinical and Laboratory Standards Institute (CLSI) guidelines against minocycline, tetracycline, doxycycline, ampicillin, streptomycin, trimethoprim-sulfamethoxazole, nalidixic acid, norfloxacin, ciprofloxacin and levofloxacin. Also, the role of efflux pump in defense of Shigella against tetracycline was investigated by Minimum Inhibitory Concentration (MIC) with and without an efflux pump inhibitor. Detection of tetA, tet $B$, tet $C$ and tetD genes in Shigella was evaluated by conventional Polymerase Chain Reaction (PCR) and real time PCR.

Results: Molecular identification revealed a prevalence of $14 \%$ for Shigella flexneri and $86 \%$ for Shigella sonnei. Minimum Inhibitory Concentration (MIC) of $90 \%$ of resistant isolates was changed in the presence CCCP. Results of conventional PCR exhibited that $66 \%$ of isolates were positive for tetA, while according to real time PCR method, $90 \%$ of isolates carried tetA. Positive results for tet $B$ were $12 \%$ and $18 \%$ by conventional and real time PCR methods, respectively. No positive results were detected for tet $C$ and tetD. Also, tet $B$ was detected only in S. flexneri while tetA was detected in both S. flexneri and S. sonnei.

Conclusion: It seems that efflux-mediated tetracycline resistance to tetracycline in $S$. flexneri can be related to tetB, however resistance in $S$. sonnei can be related to the expression of tetA.

Corresponding Information: Dr. Maliheh Nobakht, Antimicrobial Resistance research center, Iran University of Medical science, Tehran, Iran. Tel: +982186704566 Email: nobakht@yahoo.com

Copyright $\odot$ 2016, IRANIAN JOURNAL OF PATHOLOGY. This is an open-access article distributed under the terms of the Creative Commons Attribution-noncommercia 4.0 International License which permits copy and redistribute the material just in noncommercial usages, provided the original work is properly cited.

\section{Introduction}

Shigella, a member of the Enterobacteriaceae family, is considered as a health problem across the world. Shigellosis is a self-limiting infectious disease in humans that is caused by Shigella, however, morbidity and mortality rates are highest among young children, elderly and immunocompromised patients. Upon antibiotic 
therapy, duration of symptoms and the transmission rate is reduced by shortening the period of Shigella excretion. However, life-threatening complications can occur in severe cases with Multi-Drug Resistant (MDR) Shigella, which defines the ability of organisms to withstand the inhibitory effect of at least one agent in $\geq 3$ antimicrobial categories (1)(2)(3).

Over the past few decades, research in Iran (2), Malaysia (4), and West Nepal (5) revealed that Shigella is resistant to used traditional antimicrobials, similar to other bacteria. The rapid emergence of antimicrobial resistance is the public health is a concern that must be controlled (6).

The main mechanisms of Antimicrobial Resistance (AMR) are target site changes, production of an enzyme, reduced drug accumulation by the efflux pump or diminishing the permeability that can be inherent or adventitious. Control of antibiotic resistance is achieved by acquisition and dissemination of genes, through mobile genetic elements or mutations (7).

Tetracyclines, which were discovered in the 1940s, are broad-spectrum antibiotics for human, animals and plants. The first tetracycline-resistant bacteria, Shigella, was isolated in 1953, however, nowadays the majority of Shigella spp. have become resistant to it (8)(9).

The key mechanism of resistance to tetracycline arises due to the efflux pump and ribosomal protection system, which are under the control of structural and regulatory genes. Efflux pump genes code membrane proteins which export tetracycline from the cell that render it ineffective. Twenty-nine different tetracycline resistance (tet) genes were identified in gram positive and gram negative bacteria; eighteen of the Tet genes encode efflux pump, and it has been identified that tetA, tetB, tetC, tetD, tet $E$, tet $G$, tetH, tetI, tetJ, tetY, tet (30) and tet (31) are found in gram negative bacteria. Some of studies discovered tet $\mathrm{A}$, tet $\mathrm{B}$, tet $\mathrm{C}$ and tet $\mathrm{D}$ genes in Shigella, while the Antibiotic Resistance Genes Database (ARDB) does not report tetC for Shigella $(8)(9)(10)$.
Efflux pumps belong to the six different groups, coding tetracycline resistance, which extrude tetracycline-cation complexes out of the bacteria for protons. Group 1 including tetA, tetB tetC and tet $D$, are frequently found in Shigella (10).

This study aimed to investigate tetA, tetB, tet $C$ and tet $D$ genes and the effect of efflux pump inhibitors on Shigella tetracycline resistant isolates.

Materials and Methods

\section{Isolates}

This study was conducted on 50 Shigella isolates collected from children diarrheic stools in Tehran, Iran (from November 2012 to October 2013). All of the isolates were identified and confirmed using conventional biochemical tests, during year 2015 (11) .

Serogrouping of Shigella isolates was done by slide agglutination assay using A, B, C and D antisera (Baharafshan Institute of Research \& Development, Tehran, Iran). Polymerase Chain Reaction (PCR) assay targeting the ipaH (for genus Shigella), rfc (for species Shigella flexneri), and wbgZ (for species Shigella sonnei) genes was performed, Table 1 (12) (13).

\section{Antimicrobial Susceptibility Testing}

The susceptibility of isolates was examined using the disk diffusion method, in accordance with Clinical and Laboratory Standards Institute (CLSI 2015 ) guidelines (14). The antibiotic susceptibility of Shigella isolates was examined against the following antibiotics (MAST Company, Merseyside, and U.K): minocycline (30 $\mu \mathrm{g})$, tetracycline $(30 \mu \mathrm{g})$, doxycycline $(30 \mu \mathrm{g})$, ampicillin $(10 \mu \mathrm{g})$, streptomycin $(10 \mu \mathrm{g})$, trimethoprim-sulfamethoxazole $(25 \mu \mathrm{g})$, nalidixic acid $(30 \mu \mathrm{g})$, norfloxacin $(10 \mu \mathrm{g})$, ciprofloxacin (5 $\mu \mathrm{g})$ and levofloxacin $(5 \mu \mathrm{g})$ on Muller -Hinton agar. This study was conducted for all of isolates in duplicates and Escherichia coli ATCC 25922 was used as a quality control strain in susceptibility testing. 
Table 1. Primers Used in This Study

\begin{tabular}{|c|c|c|c|c|}
\hline Primer & Primer sequence (5'to 3') & $\begin{array}{l}\text { Annealing } \\
\text { temperature } \\
\text { oc }\end{array}$ & $\begin{array}{l}\text { Product size } \\
\text { in } \\
\text { bp }\end{array}$ & $\begin{array}{l}\text { Presence of } \\
\text { Genes\% }\end{array}$ \\
\hline$i p a H(\mathrm{~F})$ & $\begin{array}{l}\text { GTTCCTTGACCGCCTTTCCGATACC } \\
\text { GTC }\end{array}$ & 60 & 619 & 100 \\
\hline $\operatorname{ipaH(R)}$ & $\begin{array}{l}\text { GCCGGTCAGCCACCCTCTGAGAGT } \\
\text { AC }\end{array}$ & & & \\
\hline$w b g Z(\mathrm{~F})$ & TCT GAATATGCCCTCTACGCT & 60 & 430 & 86 \\
\hline$w b g Z(\mathrm{R})$ & GACAGAGCCCGAAGAACCG & & & \\
\hline$r f c(\mathrm{~F})$ & TTTATGGCTTCTTTGTCGG & 60 & 537 & 14 \\
\hline$r f c(\mathrm{R})$ & CTGCGTGATCCGACCATG & & & \\
\hline $\operatorname{tet} A(\mathrm{~F})$ & GCTGCAAGCAATGTTGTCCA & 59 & 190 & 66 \\
\hline $\operatorname{tet} A(\mathrm{R})$ & CAGGCAGAGCAAGTAGAGGG & & & \\
\hline $\operatorname{tet} B(\mathrm{~F})$ & CGCTAACCACTTTGGCGTAT & 59 & 211 & 12 \\
\hline $\operatorname{tet} B(\mathrm{R})$ & AGCTCCTGTGATCCCTGAAA & & & \\
\hline $\operatorname{tet} C(\mathrm{~F})$ & CTTGAGAGCCTTCAACCCAG & 55 & 418 & 0 \\
\hline $\operatorname{tet} C(\mathrm{R})$ & ATGGTCGTCATCTACCTGCC & & & \\
\hline $\operatorname{tet} D(\mathrm{~F})$ & TGGGCAGATGGTCAGATAAG & 53 & 787 & 0 \\
\hline $\operatorname{tet} D(\mathrm{R})$ & CAGCACACCCTGTAGTTTTC & & & \\
\hline $\operatorname{rps} L(\mathrm{~F})$ & TACATCGGTGGTGAAGGTCA & 59 & 154 & 100 \\
\hline $\operatorname{rpsL}(\mathrm{R})$ & ACTTGGAACGAGCCTGCTTA & & & \\
\hline
\end{tabular}

\section{Determination of Minimal Inhibitory} Concentration (MIC) with and without efflux pump inhibitor

Tetracycline resistant isolates in Disk diffusion method were used for Minimum Inhibitory Concentration (MIC) determination.

Determination of MIC for tetracycline was achieved by micro broth dilution procedure in the range of 0.5 to $1024 \mu \mathrm{g} / \mathrm{mL}$ with and without efflux pump inhibitor. Carbonyl cyanide mchlorophenylhydrazone (CCCP) was used as an efflux pump inhibitor at final concentration of 50 $\mu \mathrm{g} / \mathrm{mL}(15)(16)$.

Then, effect of CCCP on growth of Shigella isolates and Escherichia coli (as a control) was examined (15). The isolates with tetracycline MIC of $\leq 4 \mu \mathrm{g} / \mathrm{mL}$ and $\geq 16 \mu \mathrm{g} / \mathrm{mL}$ were considered as susceptible and resistant, respectively, according to CLSI guidelines.

\section{DNA Extraction}

All of Shigella isolates were grown at $37{ }^{\circ} \mathrm{C}$ in Luria-Bertani (LB) broth media. Subsequently, 2 $\mathrm{mL}$ of overnight cultures were centrifuged and DNA extracted from the sediment sample using a DNA extraction kit (Exgene Cell SV kit Gene All Biotechnology Co. Ltd Korea).

Purified genomic DNA was stored in sterile DNase free tubes for PCR screening.

\section{Oligonucleotides used in Polymerase Chain Reaction}

Polymerase Chain Reaction amplification of $i p a H, w b g Z, r f c$, tet $\mathrm{C}$ and tetD genes was performed with primers used in previous studies (12)(13)(17). Other primers (tetA and tetB) were selected based on the sequences available on GenBank for each gene and then Primer3PlusBioinformatics was used to generate the candidate primer pairs. All of primers used in this study were synthesized by the TAGC Company (Tag Copenhagen A/S Kong Georgs Vej 12 DK-2000 Frederiksberg Denmark); primer sequences are listed in Table 1. Stock suspension (100 Pmol) was made in molecular grade water and stored at $70^{\circ} \mathrm{C}$; all of primers were diluted to $10 \mathrm{Pmol}$ before use.

\section{Conventional Polymerase Chain Reaction}

Originally, PCR was performed to detect the $i p a H$ gene for confirming isolates as genus of Shigella, and then presence of $w b g Z, r f c$, tet $A$, tet $B$ , tet $C$ and tet $D$ genes was assessed. The PCR conditions were as follows: initial denaturation step at $94^{\circ} \mathrm{C}$ for 5 minutes, followed by 30 cycles consisting of denaturation (at $94^{\circ} \mathrm{C}$ for 1 minute), annealing (1 minute, separately adjusted for each set of primer pair, according Table1), and extension (at $72{ }^{\circ} \mathrm{C}$ for 1 minute), followed by a 
final extension step at $72{ }^{\circ} \mathrm{C}$ for 5 minutes. Shigella flexneri ATCC 9290 and S. sonnei ATCC 1202 were used as controls in each assay.

Finally, an agarose gel was used to assess the PCR results.

\section{RNA Extraction and cDNA Synthesis}

All of isolates were cultured in LB agar media at $37{ }^{\circ} \mathrm{C}$. One colony from each isolate was suspended in $1 \mathrm{~mL}$ of $\mathrm{LB}$ broth media and incubated at $37^{\circ} \mathrm{C}$ for 18 to 24 hours.

Next, concentration of bacterial suspension was adjusted to $10^{7} \mathrm{cfu} / \mathrm{mL}$ by OD in $625 \mathrm{~nm}$, and

400 microliter of bacterial suspension was centrifuged (3000 rpm/10 minutes). After centrifugation the supernatant was removed, the bottom sediment was resuspended in sterile normal saline, followed by another centrifugation. Subsequent to two washes, lysis buffer $(340 \mu \mathrm{L})$, SDS $(30 \mu \mathrm{L})$, carrier RNA $(10 \mu \mathrm{L})$ and proteinase $\mathrm{K}(20 \mu \mathrm{L})$ were added to bacterial cell tubes. RNA was extracted by a kit and automated Mag Core Nucleic Acid Extractor.

Immediately after, $2 \mu \mathrm{L}$ of RNA extracts was treated with mixture of DNase $(2 \mu \mathrm{L})$ and buffer $(2$ $\mu \mathrm{L})$ at $37^{\circ} \mathrm{C} / 30$ minutes. Subsequently, EDTA (2 $\mu \mathrm{L}$ ) was added and incubated at $65^{\circ} \mathrm{C}^{\prime} 10$ minutes.

Purified genomic RNA that was collected in sterile DNase free tubes was used to synthesize PCR cDNA.

In order to control quality of RNA extraction, 5 $\mu \mathrm{L}$ treated RNA and $5 \mu \mathrm{L}$ untreated were used for agarose gel electrophoresis. Also, concentration and purity of RNA were assessed by measuring the ratio of UV absorbance at $260 \mathrm{~nm}$ and $280 \mathrm{~nm}$, using a Nano Drop 2000C spectrophotometer.

Extracted RNA was used to synthesize cDNA by Revert Aid First Strand cDNA Synthesis kit (Thermo, Dreieich) and Step One plus (ABI). Also, concentration and purity of cDNA was assessed, and the cDNA was stored in sterile DNase free tubes at $-20^{\circ} \mathrm{C}$.

Evaluation of gene expression by real time Polymerase Chain Reaction

Gene expression analysis was performed by Evergreen kit (Maxima ${ }^{\circledR} \quad$ SYBR Green/Fluorescein qPCR Master Mix) in Step One plus (ABI) and ECO (Illumina USA) instruments, using tet $A$ and tet $B$ specific primers for efflux pump. The $r p s L$ gene was chosen as a reference primer housekeeping gene (Table 1). Normalization of cDNA and primers concentration was done for each reaction, the volume of cDNA for each isolate was adjusted to $20 \mathrm{ng}$ per reaction. The real time PCR conditions of initial denaturation of 10 minutes at $95^{\circ} \mathrm{C}, 40$ cycles of 15 seconds at $95^{\circ} \mathrm{C}$ for denaturation, 45 seconds annealing and 1 -minute at $72^{\circ} \mathrm{C}$ for extension, and at $72^{\circ} \mathrm{C}$ for 5 minutes, followed by a melting curve analysis. Calculation of gene expression was done using comparative quantification of $2^{(\Delta \Delta C t)}$-based on Pfaffl method (18). Amplification efficiency was determined from analysis of a serial dilution of a control strain cDNA (at certain concentrations). Analysis of data was performed with Step One Software v2.3, and qPCR products were used for electrophoresis on agarose gel for controlling the results. Mean values of duplicated runs of each isolate in real time PCR was used for analysis.

\section{Results}

Isolates

A total of 50 Shigella spp. were isolated during the period of the study between November 2012 and October 2013. The isolates of Shigella were identified by conventional biochemical tests and sero-grouping method. Among the 50 Shigella isolates confirmed by PCR, $16 \% \quad(\mathrm{n}=8)$ was identified as Shigella flexneri ( $S$. flexneri) and $84 \%(\mathrm{n}=42)$ as Shigella sonnei ( $S$. sonnei). Species-specific PCR analyses of ipaH gene confirmed the identity of all isolates as Shigella spp. Moreover, amplification of the genes $w b g Z$ and $r f c$ confirmed serogrouping results (Table1).

\section{Antimicrobial susceptibility testing}

The results of antimicrobial susceptibility of Shigella spp. demonstrated that all of the isolates were MDR and resistant to three or more classes of antibiotics.

According to the results of antimicrobial susceptibility testing listed in Table $2,96 \%$ of all isolates were resistant to tetracycline, $94 \%$ to doxycycline, and $2 \%$ to minocycline 
Table 2. Results of Antimicrobial Susceptibility

\begin{tabular}{|lcc|}
\hline Antibiotics & \multicolumn{2}{c|}{ Percentage of isolates } \\
\hline Ampicillin & Sensitive & Resistant \\
\hline Ciprofloxacin & 76 & 24 \\
\hline Doxycycline & 98 & 2 \\
\hline Levofloxacin & 6 & 94 \\
\hline Minocycline & 100 & 0 \\
\hline Nalidixic Acid & 98 & 2 \\
\hline Norfloxacin & 82 & 18 \\
\hline Streptomycin & 100 & 0 \\
\hline Tetracycline & 0 & 100 \\
\hline Trimethoprim-sulfamethoxazole & 2 & 96 \\
\hline
\end{tabular}

Table 3. Results of Minimum Inhibitory Concentration With and Without Efflux Pump Inhibitor

\begin{tabular}{|c|c|c|c|c|c|c|c|c|c|c|c|}
\hline Range of MIC & 512 & 256 & 128 & 64 & 32 & 16 & 8 & 4 & 2 & 1 & 0.5 \\
\hline Without CCCP & $\begin{array}{l}2 \% \\
(\mathrm{n}=1)\end{array}$ & $\begin{array}{l}78 \% \\
(n=39)\end{array}$ & $\begin{array}{l}16 \% \\
(\mathrm{n}=8)\end{array}$ & $0 \%$ & $0 \%$ & $0 \%$ & $0 \%$ & $\begin{array}{l}4 \% \\
(\mathrm{n}=2)\end{array}$ & $0 \%$ & $0 \%$ & $0 \%$ \\
\hline With CCCP & $0 \%$ & $6 \%$ & $40 \%$ & $20 \%$ & $6 \%$ & $12 \%$ & $0 \%$ & $4 \%$ & $0 \%$ & $2 \%$ & $10 \%$ \\
\hline No change & $0 \%$ & $4 \%$ & $2 \%$ & $0 \%$ & $0 \%$ & $0 \%$ & $0 \%$ & $4 \%$ & $0 \%$ & $0 \%$ & $0 \%$ \\
\hline
\end{tabular}

CCCP: Inhibitor n: Number of isolates

\section{Minimum Inhibitory Concentration Test}

All tetracycline resistant isolates were subjected to MIC determination with or without efflux pump inhibitor (CCCP). All of the isolates showed resistance by the MIC method (Table 3).

\section{Extraction of nucleic acid}

Majority of extracted nucleic acids (RNA, cDNA) indicated the acceptable ratio of UV absorbance at $260 \mathrm{~nm}$ and $280 \mathrm{~nm}$ for assessing the purity of DNA (about 2) and electrophoresis. A few extractions of RNA with poor results of electrophoresis were repeated.

\section{Conventional PCR}

The IpaH gene amplified with PCR, visualized a 619-bp band on agarose gel for all isolates and confirmed them as the genus of Shigella. In addition, amplification of $w b g Z$ and $r f c$ genes revealed $430 \mathrm{bp}$ and $537 \mathrm{bp}$ bands, confirming
Shigella isolates as S. sonnei and S. flexneri, respectively.

Polymerase Chain Reaction amplification of Shigella isolates showed that $66 \%$ of isolates were positive for tetA, while only $12 \%$ of them were positive for $t e t B$. Neither of the isolates was positive for tetC and tetD (Table 1).

\section{Real Time Polymerase Chain Reaction}

As Table 4 shows, PCR analysis of isolates demonstrated $78 \%$ against $12 \%$ for presence of tet $A$ and tet $B$ (Table 4).

Expression of tetB gene was seen in $S$. flexneri isolates, which were resistant to tetracycline.

Shigella sonnei isolates did not express tetA, and their MIC did not change after using CCCP (Table 4). 
Table 4. Results of Expression of tet $\mathrm{A}$ and tet $\mathrm{B}$ Genes by Real Time Polymerase Chain Reaction

\begin{tabular}{|c|c|c|c|c|c|c|c|c|c|}
\hline $\begin{array}{c}\text { Isolat } \\
\text { es }\end{array}$ & $\begin{array}{c}\text { Serogrou } \\
\text { p }\end{array}$ & $\begin{array}{c}\text { Resistance } \\
\text { to } \\
\text { Tetracycline }\end{array}$ & $\begin{array}{c}\text { MIC } \\
\text { Withou } \\
\text { t CCCP }\end{array}$ & $\begin{array}{c}\text { MIC } \\
\text { With } \\
\text { CCC } \\
\text { P }\end{array}$ & ${ }^{1}$ tetA & $\begin{array}{c}\text { Expressi } \\
\text { on of } \\
\text { tetA } \\
\text { (fold) }\end{array}$ & ${ }^{2}$ tetB & $\begin{array}{c}\text { Express } \\
\text { ion of } \\
\text { tetB } \\
\text { (fold) }\end{array}$ & $\begin{array}{l}\text { Pattern of } \\
\text { resistance }\end{array}$ \\
\hline 1 & ${ }^{4} \mathrm{D}$ & ${ }^{6} \mathrm{R}$ & 512 & 256 & ${ }^{8} \mathrm{P}$ & 8.9 & $\mathrm{~N}$ & ${ }^{3} 0$ & T,D,SXT,S \\
\hline 2 & $\mathrm{D}$ & $\mathrm{R}$ & 256 & 128 & $\mathrm{P}$ & 4.18 & $\mathrm{~N}$ & 0 & T,D,SXT,S,AM \\
\hline 3 & D & $\mathrm{R}$ & 256 & 128 & $\mathrm{P}$ & 7.3 & $\mathrm{~N}$ & 0 & T,D,SXT,S,AM \\
\hline 4 & $\mathrm{D}$ & $\mathrm{R}$ & 256 & 128 & $\mathrm{P}$ & 7.97 & $\mathrm{~N}$ & 0 & T,D,SXT,S,AM \\
\hline 5 & D & $\mathrm{R}$ & 256 & 128 & $\mathrm{P}$ & 1.13 & $\mathrm{~N}$ & 0 & T,D,SXT,S,NA \\
\hline 6 & $\mathrm{D}$ & $\mathrm{R}$ & 256 & 128 & $\mathrm{P}$ & 5.4 & $\mathrm{~N}$ & 0 & T,D,SXT,S \\
\hline 7 & $\mathrm{D}$ & $\mathrm{R}$ & 256 & 128 & $\mathrm{P}$ & 7.3 & $\mathrm{~N}$ & 0 & $\mathrm{~T}, \mathrm{D}, \mathrm{SXT}, \mathrm{S}$ \\
\hline 8 & $\mathrm{D}$ & $\mathrm{R}$ & 256 & 128 & $\mathrm{P}$ & 3.11 & $\mathrm{~N}$ & 0 & T,D,SXT,S \\
\hline 9 & $\mathrm{D}$ & $\mathrm{R}$ & 256 & 128 & ${ }^{9} \mathrm{~N}$ & 0.61 & $\mathrm{~N}$ & 0 & T,D,SXT,S \\
\hline 10 & $\mathrm{D}$ & $\mathrm{R}$ & 256 & 128 & $\mathrm{~N}$ & 0.53 & $\mathrm{~N}$ & 0 & T,D,SXT,S \\
\hline 11 & D & $\mathrm{R}$ & 256 & 128 & $\mathrm{P}$ & 2.98 & $\mathrm{~N}$ & 0 & T,D,SXT,S \\
\hline 12 & $\mathrm{D}$ & $\mathrm{R}$ & 256 & 128 & $\mathrm{P}$ & 4 & $\mathrm{~N}$ & 0 & T,D,SXT,S \\
\hline 13 & D & $\mathrm{R}$ & 256 & 128 & $\mathrm{P}$ & 1.98 & $\mathrm{~N}$ & 0 & T,D,SXT,S \\
\hline 14 & $\mathrm{D}$ & $\mathrm{R}$ & 256 & 128 & $\mathrm{P}$ & 9.1 & $\mathrm{~N}$ & 0 & T,D,SXT,S \\
\hline 15 & $\mathrm{D}$ & $\mathrm{R}$ & 256 & 128 & $\mathrm{P}$ & 3.6 & $\mathrm{~N}$ & 0 & T,D,SXT,S \\
\hline 16 & $\mathrm{D}$ & $\mathrm{R}$ & 256 & 128 & $\mathrm{P}$ & 0.97 & $\mathrm{~N}$ & 0 & T,D,SXT,S \\
\hline 17 & $\mathrm{D}$ & $\mathrm{R}$ & 256 & 128 & $\mathrm{P}$ & 1.9 & $\mathrm{~N}$ & 0 & T,D,SXT,S \\
\hline 18 & $\mathrm{D}$ & $\mathrm{R}$ & 256 & 128 & $\mathrm{P}$ & 0.97 & $\mathrm{~N}$ & 0 & T,D,SXT,S \\
\hline 19 & D & $\mathrm{R}$ & 256 & 128 & $\mathrm{~N}$ & 0.81 & $\mathrm{~N}$ & 0 & T,D,SXT,S \\
\hline 20 & $\mathrm{D}$ & $\mathrm{R}$ & 256 & 128 & $\mathrm{~N}$ & 0.61 & $\mathrm{~N}$ & 0 & T,D,SXT,S \\
\hline 21 & $\mathrm{D}$ & $\mathrm{R}$ & 256 & 64 & $\mathrm{P}$ & 8,9 & $\mathrm{~N}$ & 0 & T,D,SXT,S,AM \\
\hline 22 & $\mathrm{D}$ & $\mathrm{R}$ & 256 & 64 & $\mathrm{P}$ & 2.8 & $\mathrm{~N}$ & 0 & T,D,SXT,S,AM \\
\hline 23 & $\mathrm{D}$ & $\mathrm{R}$ & 256 & 64 & $\mathrm{~N}$ & 0.29 & $\mathrm{~N}$ & 0 & T,D,SXT,S,NA \\
\hline 24 & $\mathrm{D}$ & $\mathrm{R}$ & 256 & 64 & $\mathrm{P}$ & 1.01 & $\mathrm{~N}$ & 0 & T,D,SXT,S \\
\hline 25 & D & $\mathrm{R}$ & 256 & 64 & $\mathrm{P}$ & 4.5 & $\mathrm{~N}$ & 0 & $\mathrm{~T}, \mathrm{D}, \mathrm{SXT}, \mathrm{S}$ \\
\hline 26 & $\mathrm{D}$ & $\mathrm{R}$ & 256 & 64 & $\mathrm{~N}$ & 0.76 & $\mathrm{~N}$ & 0 & T,D,SXT,S \\
\hline 27 & $\mathrm{D}$ & $\mathrm{R}$ & 256 & 64 & $\mathrm{P}$ & 6.53 & $\mathrm{~N}$ & 0 & T,D,SXT,S \\
\hline 28 & $\mathrm{D}$ & $\mathrm{R}$ & 256 & 64 & $\mathrm{P}$ & 4.7 & $\mathrm{~N}$ & 0 & T,D,SXT,S \\
\hline 29 & $\mathrm{D}$ & $\mathrm{R}$ & 256 & 64 & $\mathrm{~N}$ & 0.67 & $\mathrm{~N}$ & 0 & T,D,SXT,S \\
\hline 30 & $\mathrm{D}$ & $\mathrm{R}$ & 256 & 64 & $\mathrm{~N}$ & 0.34 & $\mathrm{~N}$ & 0 & T,D,SXT,S \\
\hline 31 & $\mathrm{D}$ & $\mathrm{R}$ & 256 & 32 & $\mathrm{~N}$ & 0.31 & $\mathrm{~N}$ & 0 & T,D,SXT,S,AM \\
\hline 32 & $\mathrm{D}$ & $\mathrm{R}$ & 256 & 32 & $\mathrm{P}$ & 11.9 & $\mathrm{~N}$ & 0 & T,D,SXT,S,NA \\
\hline 33 & $\mathrm{D}$ & $\mathrm{R}$ & 128 & 32 & $\mathrm{P}$ & 11.8 & $\mathrm{~N}$ & 0 & $\mathrm{~T}, \mathrm{D}, \mathrm{SXT}, \mathrm{S}, \mathrm{NA}$ \\
\hline 34 & $\mathrm{D}$ & $\mathrm{R}$ & 256 & 16 & $\mathrm{P}$ & 3.2 & $\mathrm{~N}$ & 0 & T,D,SXT,S,NA \\
\hline 35 & D & $\mathrm{R}$ & 256 & 16 & $\mathrm{P}$ & 5.8 & $\mathrm{~N}$ & 0 & T,D,SXT,S,NA \\
\hline 36 & $\mathrm{D}$ & $\mathrm{R}$ & 256 & 16 & $\mathrm{~N}$ & 0.78 & $\mathrm{~N}$ & 0 & $\mathrm{~T}, \mathrm{D}, \mathrm{SXT}, \mathrm{S}, \mathrm{NA}$ \\
\hline 37 & $\mathrm{D}$ & $\mathrm{R}$ & 256 & 16 & $\mathrm{P}$ & 8.6 & $\mathrm{~N}$ & 0 & T,D,SXT,S \\
\hline 38 & $\mathrm{D}$ & $\mathrm{R}$ & 256 & 16 & $\mathrm{P}$ & 4.8 & $\mathrm{~N}$ & 0 & T,D,SXT,S \\
\hline 39 & $\mathrm{D}$ & $\mathrm{R}$ & 256 & 16 & $\mathrm{P}$ & 6.3 & $\mathrm{~N}$ & 0 & T,D,SXT,S \\
\hline 40 & $\mathrm{D}$ & $\mathrm{R}$ & 256 & 256 & $\mathrm{P}$ & 0 & $\mathrm{~N}$ & 0 & T,D,SXT,S \\
\hline 41 & $\mathrm{D}$ & $\mathrm{R}$ & 256 & 256 & $\mathrm{P}$ & 0 & $\mathrm{~N}$ & 0 & T,D,SXT,S \\
\hline 42 & $\mathrm{D}$ & $\mathrm{R}$ & 128 & 128 & $\mathrm{~N}$ & 0 & $\mathrm{~N}$ & 0 & T,D,SXT,S \\
\hline 43 & ${ }^{5} \mathrm{~B}$ & $\mathrm{R}$ & 128 & 1 & $\mathrm{~N}$ & 0 & $\mathrm{P}$ & 5.69 & T,MIN,SXT,S,AM \\
\hline 44 & $\mathrm{~B}$ & $\mathrm{R}$ & 128 & 0.5 & $\mathrm{~N}$ & 0 & $\mathrm{P}$ & 3.56 & T,D,SXT,S,AM \\
\hline 45 & B & $\mathrm{R}$ & 128 & 0.5 & $\mathrm{~N}$ & 0 & $\mathrm{P}$ & 2.44 & T,D,SXT,S,AM \\
\hline 46 & B & $\mathrm{R}$ & 128 & 0.5 & $\mathrm{~N}$ & 0 & $\mathrm{P}$ & 0.88 & $\mathrm{~T}, \mathrm{D}, \mathrm{S}, \mathrm{AM}$ \\
\hline 47 & B & $\mathrm{R}$ & 128 & 0.5 & $\mathrm{~N}$ & 0 & $\mathrm{P}$ & 2.51 & T,D,SXT,S \\
\hline 48 & B & $\mathrm{R}$ & 128 & 0.5 & $\mathrm{~N}$ & 0 & $\mathrm{P}$ & 0.36 & T,SXT,S \\
\hline 49 & B & ${ }^{7} \mathrm{~S}$ & 4 & 4 & $\mathrm{P}$ & 0 & $\mathrm{~N}$ & 0 & SXT,S,NA \\
\hline 50 & B & $\mathrm{S}$ & 4 & 4 & $\mathrm{P}$ & 0 & $\mathrm{~N}$ & 0 & $\begin{array}{c}\text { SXT,S,AM,NA,CI } \\
\text { P }\end{array}$ \\
\hline
\end{tabular}

${ }^{1}$ Presence of tetA by conventional PCR ${ }^{2}$ Presence of tetA by conventional PCR ${ }^{3} 0$ : No expression ${ }^{4} \mathrm{D}=S$. sonnei ${ }^{5} B=S$. flexneri ${ }^{6} \mathrm{R}$ : Resistance ${ }^{7} \mathrm{~S}$ : Sensitive ${ }^{8} \mathrm{P}$; Positive ${ }^{9} \mathrm{~N}$ : Negative $\mathrm{MIC} \geq 16 \mu \mathrm{g} / \mathrm{ml}$ indicate resistance to tetracycline. MIC $\leq 4 \mu \mathrm{g} / \mathrm{mL}$ indicates susceptibility to tetracycline. $\mathrm{T}=$ Tetracycline $\mathrm{D}=\mathrm{D}$ oxycycline MIN=Minocycline $S=$ Streptomycin $S X T=$ trimethoprim-sulfamethoxazole AM=Ampicillin NA=Nalidixic Acid $\mathrm{CIP}=$ Ciprofloxacin 


\section{Discussion}

In concordance with the results of other studies in Iran, S. sonnei was the dominant species in this study (19)(20)(21)(22). Increasing prevalence of $S$. sonnei in other regions like the United States may be related to increasing environmental adaptation of $S$. sonnei(23)(24). All of the $S$. sonnei and $75 \%$ of S. flexneri were MDR that could lead to an emergency in treatment of shigellosis, especially because of increased resistance to first -line antimicrobial agents (Table 2).

Tetracycline was discovered in 1940, most of bacteria were susceptible to this drug in mid-1950. Resistance to tetracycline was first reported in year 1957, also tetracycline-resistant $S$. sonnei cases (35\%) were reported in 1978 (25). Nowadays, most Shigella spp., such as that of the current study (96\%), are resistant to tetracycline. Hence, tetracycline cannot be a suitable choice for treatment of shigellosis.

Moreover, Shigella isolates that were susceptible to tetracycline were also sensitive to doxycycline and minocycline. A description for difference in the rate of resistance between minocycline, doxycycline and tetracycline can refer to less use of minocycline (Table 2).

The MIC results for tetracycline showed high resistance (MIC $\geq 256 \mu \mathrm{g} / \mathrm{mL}$ ) in most of shigella isolates (Table 3). One research in Hong Kong from 1986 to 1995 demonstrated

MIC of $\geq 256 \mu \mathrm{g} / \mathrm{mL}$ for $S$. sonnei and $S$. flexneri (26) . It seems that resistance to tetracycline can be related to efflux pump, ribosomal protection system or other mechanisms (9). It is considerable that all tetracycline resistant Shigella isolates were also resistant to trimethoprim-sulfamethoxazole and streptomycin (Table 4). High rates of resistance to trimethoprim-sulfamethoxazole and tetracycline among Shigella isolates were reported in Iran and other countries (2)(27). Barman examined the relationship between simultaneous resistance to trimethoprim sulfamethoxazole and streptomycin with a $6.3-\mathrm{kb}$ plasmid and observed that the isolates were resistant to tetracycline as well (28). This phenomenon leads us to another factor that can be the cause of one or more antimicrobial resistance in bacteria.

It has been observed that in the presence of $\mathrm{CCCP}$, as the inhibitor of efflux pump, MIC value is decreased. Moreover, CCCP can change some resistant isolates to sensitive ones, and it can be concluded that inhibiting of efflux pump decreases MIC (Table 3). However, MIC of $10 \%$ of resistant isolates did not change in the presence CCCP. Also, MIC of most isolates was reduced, yet they remained resistant. Thus, the other factors (except efflux pump) might lead to resistance in isolates (Table 3).

It seems that resistance to tetracycline can be associated with efflux pump, ribosomal protection system or other mechanisms (9).

In order to evaluate efflux-mediated tetracycline resistance, the presence of tet A, tet $B$, tet $C$ and tetD genes in DNA of Shigella isolates were investigated by PCR (10). Neither of the isolates showed amplification of tetC and tetD, however, they were positive for $66 \%$ of tetA and $12 \%$ of tetB (Table 4 ). The study of Martinez et al. (1986) demonstrated the presence of tetC in $S$. flexneri (12.5\%) and S. sonnei (72.5\%) while tetD was observed only in S. sonnei (8\%). The study of Hartman et al. (2003) revealed that $3.1 \%$ of $S$. sonnei harbored tetC, yet this was negative for $S$. flexneri (29). Also, TetD was observed in S. sonnei and $S$. dysenteriae serotype 1 (30). Inconsistency between the results of our study $(n=50)$ and that of Hartman $(n=369)$ and Martinez $(n=33)$ can be related to different number of isolates (30)(29). All of our isolates with tet $B$ were defined as S. flexneri and isolates positive for tetA defined as $S$. sonnei and S. flexneri (Table 4). Results of the study of Mandomando et al. revealed that $15 \%$ of Shigella isolates were positive for $t e t A$ and $79 \%$ for $\operatorname{tet} B(1)$. The difference between the study of Mandomando and the present research may be related to low ratio of $S$. sonnei $(\mathrm{n}=15)$ against $S$. flexneri $(\mathrm{n}=94)$, as tetA was seen in $S$. sonnei more than $S$. flexneri (1). It is important to note that two susceptible isolates to tetracycline were positive for tetA yet negative for tetB. This result shows that the presence of tetA cannot explain resistance to tetracycline in S. flexneri. Most of the resistant isolates to tetracycline were positive for tetA and 
negative for $t e t B$. In the presence of $\mathrm{CCCP}$, the value of MIC for tetracycline was reduced (one fold and more) yet the isolates stayed resistant.

It can be concluded that resistance to tetracycline in $S$. sonnei may be related to expression of tetA, but in these isolates other tetracycline-resistant factors are involved in resistance. On the other hand, two $S$. sonnei and two $S$. flexneri were positive for tetA, according to conventional PCR, while expression of tetA was negative by real time PCR. Also, in the presence of CCCP, MIC value of both isolates had no change. It can be concluded that high resistance of these two isolates is due to other factors other than the efflux pump.

Six tetracycline resistant isolates ( $S$. flexneri), positive for tetB (according to conventional PCR and real time PCR), were changed to become susceptible by adding CCCP. It can be concluded that resistance to tetracycline in $S$. flexneri may be related to expression of $t e t B$.

Ten isolates ( $S$. sonnei) were negative for tetA by conventional PCR, but they were expressed using real time PCR. Comparison of conventional PCR and real time PCR results showed that the detection of genes by real time PCR is more reliable (Table 4).

\section{References}

1. Mandomando I, Jaintilal D, Pons MJ, Vallès X, Espasa M, Mensa L, et al. Antimicrobial susceptibility and mechanisms of resistance in Shigella and Salmonella isolates from children under five years of age with diarrhea in rural Mozambique. Antimicrobial Agents and Chemotherapy. 2009. p. 2450-4.

2. Pourakbari B, Mamishi S, Mashoori N, Mahboobi $\mathrm{N}$, Ashtiani MH, Afsharpaiman S, et al. Frequency and antimicrobial susceptibility of Shigella species isolated in Children Medical Center Hospital, Tehran, Iran, 20012006. Brazilian J Infect Dis [Internet]. 2010;14(2):153$7 . \quad$ Available from: http://www.sciencedirect.com/science/article/pii/S1413 867010700295 .

3. Toro C, Arroyo A, Sarria A, Iglesias N, Enríquez A, Baquero M, et al. Shigellosis in Subjects with Traveler's Diarrhea Versus Domestically Acquired Diarrhea: Implications for Antimicrobial Therapy and Human Immunodeficiency Virus Surveillance. Am J Trop Med Hyg. ASTMH; 2015;93(3):491-6.

\section{Conclusion}

The mechanism of resistances to antibiotics can be different among species of a genus of bacteria. Increased resistance to antibiotics is one of the most important challenges around world, hence in order to prevent the emergence of resistant strains and to choose an appropriate treatment, the susceptibility test for each isolate should be more carefully monitored.

High resistance to tetracycline in Shigella isolates means that it cannot be a suitable choice for treatment of shigellosis but using suitable efflux pump inhibitors may change this result.

Resistance to tetracycline in $S$. sonnei and $S$. flexneri may be related to tetA and tetB genes, respectively.

\section{Acknowledgements}

This study was supported by Iran University of Medical Sciences with grant number 92-02-13421592.

Conflict of Interests: The authors declare that there was no conflict of interest.

4. Thong K-L, Hoe CH, Koh YT, Yasin RM. Prevalence of multidrug-resistant Shigella isolated in Malaysia. J Heal Popul Nutr. JSTOR; 2002;356-8.

5. Wilson G, Easow JM, Mukhopadhyay C, Shivananda PG. Isolation \& antimicrobial susceptibility of Shigella from patients with acute gastroenteritis in western Nepal. Indian J Med Res. Indian Council of Medical Research; 2006;123(2):145.

6. House W. National action plan for combating antibiotic-resistant bacteria. Accessed August. 2015;8.

7. Epstein FH, Jacoby GA, Archer GL. New mechanisms of bacterial resistance to antimicrobial agents. N Engl J Med. Mass Medical Soc; 1991;324(9):601-12.

8. Liu B, Pop M. ARDB $>$ antibiotic resistance genes database. Nucleic Acids Res. Oxford Univ Press; 2009;37(suppl 1):D443-7.

9. Rolain JM. Food and human gut as reservoirs of transferable antibiotic resistance encoding genes. Front Microbiol. 2013;4(JUN):1-10.

10. Chopra I, Roberts M. Tetracycline Antibiotics: Mode of Action, Applications, Molecular Biology, and Epidemiology of Bacterial Resistance. Microbiol Mol 
Biol Rev [Internet]. 2001;65(2):232-60. Available from: http://www.facm.ucl.ac.be/Full-texts-

FACM/Vanbambeke-2006-4.pdf.

11. Services M. UK Standards for Microbiology Investigations. Bacteriology. 2014;B 55(5.2):1-21.

12. Ojha SC, Yean Yean C, Ismail A, Banga Singh KK. A pentaplex PCR assay for the detection and differentiation of Shigella species. Biomed Res Int. Hindawi Publishing Corporation; 2013;2013.

13. Toma C, Lu Y, Higa N, Nakasone N, Chinen I, Baschkier A, et al. Multiplex PCR assay for identification of human diarrheagenic Escherichia coli. J Clin Microbiol [Internet]. 2003;41(6):2669-71. Available from: http://www.pubmedcentral.nih.gov/ articlerender.fcgi?artid=156568\&tool=pmcentrez\&rend ertype $=$ abstract

14. Jorgensen JH, Turnidge JD. Susceptibility Test Methods: Dilution and Disk Diffusion Methods*. American Society of Microbiology; 2015;

15. Cho H, Oh Y, Park S, Lee Y. Concentration of CCCP should be optimized to detect the efflux system in quinolone-susceptible Escherichia coli. J Microbiol. 2001;39(1):62-6.

16. Jain M, Kumar P, Goel AK. Emergence of Tetracycline Resistant Vibrio cholerae O1 Biotype El Tor Serotype Ogawa with Classical ctxB Gene from a Cholera Outbreak in Odisha, Eastern India. J Pathog. Hindawi Publishing Corporation; 2016;2016.

17. Ng L-K, Mulvey MR, Martin I, Peters GA, Johnson W. Genetic characterization of antimicrobial resistance in Canadian isolates of Salmonella serovar Typhimurium DT104. Antimicrob Agents Chemother. Am Soc Microbiol; 1999;43(12):3018-21.

18. Pfaffl MW. A new mathematical model for relative quantification in real-time RT--PCR. Nucleic Acids Res. Oxford Univ Press; 2001;29(9):e45-e45.

19. Eftekhari N, Bakhshi B, Pourshafie MR, Zarbakhsh B, Rahbar M, Hajia M, et al. Genetic diversity of Shigella spp. and their integron content. Foodborne Pathog Dis. Mary Ann Liebert, Inc. 140 Huguenot Street, 3rd Floor New Rochelle, NY 10801 USA; 2013;10(3):237-42.

20. Mardaneh J, Poor SA, Afrugh P. Prevalence of Shigella species and antimicrobial resistance patterns of isolated strains from infected pediatrics in Tehran. Int $\mathrm{J}$ Entric Pathog. 2013;1(1):28-31.
21. Dibaj R, Aslani MM, Heidarieh P, Hashemi A, Ataei B, Daei-Naser A, et al. Conventional and molecular investigation of Shigella isolates in relation to an outbreak in the area of Isfahan, Iran. Iran J Microbiol. Tehran University of Medical Sciences; 2013;5(4):339.

22. Tajbakhsh M, Migura LG, Rahbar M, Svendsen CA, Mohammadzadeh M, Zali MR, et al. Antimicrobialresistant Shigella infections from Iran: an overlooked problem? J Antimicrob Chemother. Br Soc Antimicrob Chemo; 2012;67(5):1128-33.

23. Balbi KJ, Rocha EPC, Feil EJ. The temporal dynamics of slightly deleterious mutations in Escherichia coli and Shigella spp. Mol Biol Evol. 2009;26(2):345-55.

24. Gupta A, Polyak CS, Bishop RD, Sobel J, Mintz ED. Laboratory-confirmed shigellosis in the United States, 1989-2002: epidemiologic trends and patterns. Clin Infect Dis. 2004;38(10):1372-7.

25. Hawkins W a, Dale JW. High and low level tetracycline resistance in Shigella sonnei. J Hyg (Lond). 1978;81(1):131-8.

26. Chu Y, Houang ETS, Lyon DJ, Ling JM, Ng T, Cheng AFB. Antimicrobial resistance in Shigella flexneri and Shigella sonnei in Hong Kong, 1986 to 1995. Antimicrob Agents Chemother. Am Soc Microbiol; 1998;42(2):440-3.

27. Wong MR, Reddy V, Hanson H, Johnson KM, Tsoi B, Cokes C, et al. Antimicrobial resistance trends of Shigella serotypes in New York City, 2006-2009. Microb Drug Resist [Internet]. 2010;16(2):155-61. Available from: http://ovidsp.ovid.com/ ovidweb.cgi $? \mathrm{~T}=\mathrm{JS} \& \mathrm{PAGE}=$ reference $\& \mathrm{D}=$ med $\& \mathrm{NEWS}=\mathrm{N} \& \mathrm{AN}=$ 20438349

28. Barman S, Chatterjee S, Chowdhury G, Ramamurthy T, Niyogi SK, Kumar R, et al. Plasmidmediated streptomycin and sulfamethoxazole resistance in Shigella flexneri 3a. Int J Antimicrob Agents. Elsevier; 2010;36(4):348-51.

29. Martínez-Salazar JM, Alvarez G, GomezEichelmann MC. Frequency of four classes of tetracycline resistance determinants in Salmonella and Shigella spp. clinical isolates. Antimicrob Agents Chemother. Am Soc Microbiol; 1986;30(4):630-1.

30. Hartman AB, Essiet II, Isenbarger DW, Lindler LE. Epidemiology of tetracycline resistance determinants in Shigella spp. and enteroinvasive Escherichia coli: Characterization and dissemination of tet (A)-1. J Clin Microbiol. 2003;41(3):1023-32.

\section{How to Cite This Article:}

Shahsavan S, Owlia P, Rastegar Lari A, Bakhshi B, Nobakht M. Investigation of Efflux-Mediated Tetracycline Resistance in Shigella Isolates Using the Inhibitor and Real Time Polymerase Chain Reaction Method. Iranian Journal of Pathology. 2017;12(1):53-61. 